\title{
A IMPORTÂNCIA DA LÍNGUA INGLESA NA EJA - PRÁTICAS E IDENTIDADE DO PROFESSOR
}

\section{ARTIGO DE REVISÃO}

BOREL, Jaqueline Fernandes ${ }^{1}$

BOREL, Jaqueline Fernandes. A importância da língua inglesa na EJA - práticas e identidade do professor. Revista Científica Multidisciplinar Núcleo do Conhecimento. Ano 04, Ed. 07, Vol. 05, pp. 36-46. Julho de 2019. ISSN: 2448-0959

\section{RESUMO}

Este trabalho explana a importância da aprendizagem em língua inglesa na Educação de Jovens e Adultos. A influência que esse idioma desempenha nas crianças e adolescentes, ainda sendo língua universal, exige uma participação cada vez mais ativa do indivíduo no contexto escolar. Assim, questiona-se: Como tornar os alunos da $E J A$, leitores e escritores proficientes em língua inglesa à luz da dialética do conhecimento? É necessário que a humanidade estreite seus laços através da palavra escrita ou falada em língua inglesa e que se aprimore a formação de professores, as condições de trabalho nas escolas e os problemas disciplinares ligados à motivação e atitude. Essas são questões fundamentais para que a proficiência dos conteúdos desenvolvidos em sala seja suficiente para a aprendizagem. Portanto, este estudo visa propiciar condições para que o aluno possa aprender a se expressar em uma língua estrangeira, desenvolvendo e estimulando atividades e metodologias diversificadas que promovam a vivência da língua inglesa dentro e fora da sala de aula. Assim, pode-se oferecer ao aluno, condições orais e escritas para que ele possa

\footnotetext{
${ }^{1}$ Mestranda em Educação (Grendal University). Especialista em Língua Inglesa (FERLAGOS). Especialista em EJA (FAP). Especialista em Docência do Ensino Superior (FAP). Especialista em Mídias na Educação (UESB). Graduada em Letras Português e Inglês e Literaturas (UNEB).
} 
utilizar-se da língua inglesa em seu cotidiano, desenvolvendo no mesmo, a capacidade e a habilidade de se comunicar em uma outra língua de maneira eficaz.

Palavras-chave: Aprendizagem, língua inglesa, escolas públicas, metodologias.

\section{INTRODUÇÃO}

Necessário se faz uma reflexão sobre que metodologias podem ser adotadas nas escolas públicas municipais que facilitem a aprendizagem da língua inglesa, cujo idioma está inserido no cotidiano das pessoas através da música, publicidade, internet, manuais de produtos adquiridos, entre outros. Portanto, é fundamental a busca do conhecimento, fala e entendimento pelo menos do 'básico' desse idioma. Assim, é preciso despertar esse aspecto através das leituras prévias, discussões e reflexões em sala de aula.

Este estudo se destina à implementação de metodologias diversificadas em salas dos alunos das turmas da EJA da Escola Municipal João Mendonça no Município de Teixeira de Freitas no Extremo Sul da Bahia, com o objetivo de despertar a importância do inglês na vida dos alunos e sua frequência no dia a dia. A escolha pela turma explica-se face à ideia de que a língua inglesa deve ser trabalhada na vida dos jovens, inclusive, o indicado é que se trabalhe o mais cedo possível na vida das crianças. $\mathrm{Na}$ atualidade, os jovens têm o contato com o mundo moderno cada vez mais rápido, ao entrar em uma sala de bate papo na internet, ao ouvir músicas, ir ao cinema, fazer compras em um shopping, entre outros aspectos.

Por isso, é necessário desenvolver nos jovens, o desejo de se relacionar com a língua inglesa de forma dinâmica, inserindo o idioma no cotidiano, com vistas à possibilidade de estar aprendendo com as experiências diárias. Para tanto, esse trabalho questiona: Como tornar os alunos da EJA, leitores e escritores proficientes em língua inglesa à luz da dialética do conhecimento? Este trabalho busca propiciar ao aluno condições para que ele aprenda, pratique e se expresse em uma língua estrangeira, desenvolvendo metodologias diversificadas que promovam a vivência da língua inglesa dentro e fora de sala de aula. 
São desafiadores para a educação, os avanços do ensino da língua inglesa, uma vez que é inegável seu valor instrumental para os progressos tecnocientíficos contemporâneos. Devido aos fatores supracitados, aprender a língua é tão importante como aprender uma profissão. Esse idioma tornou-se tão necessário para a vida atual que, para aprimoramento em uma atividade profissional, seja no campo da medicina, da eletrônica, física, informática, ou outro, tem-se de saber falar inglês.

\section{A MODALIDADE DE EDUCAÇÃO DE JOVENS E ADULTOS}

A Educação de Jovens e Adultos - EJA é uma modalidade de ensino que engloba os alunos que estão em defasagem idade/série e não conseguiram concluir os estudos da Educação Básica no tempo determinado. A maioria desses alunos vem de uma classe social econômica desfavorável, o que contribui para que esses educandos necessitem trabalhar e deixem de estudar para prover o seu próprio sustento e muitas vezes, o sustento dos seus familiares.

Em alguns casos, a EJA tem alunos que não conseguiram a aprovação por anos seguidos nas séries em que se encontravam. Eles não conseguem acompanhar a idade e a série necessárias ao ensino básico e sentem-se desestimulados, resolvendo assim, estudar nesta modalidade na qual encontram alunos com idade equivalente à sua e com dificuldades e/ou problemas de aprendizagem semelhantes aos seus.

Enquanto mediador da aprendizagem, o professor proporciona boas situações de aprendizagem, lançando desafios, intervindo e mediando no momento certo, para que o aluno pense e construa conhecimentos, a fim de que possa se expressar na linguagem oral e posteriormente, na escrita. Vale aqui ressaltar, a proposta curricular da EJA que informa ser basicamente através da comunicação oral que o aluno se desenvolve como participante de uma cultura (TAMAROZZI; COSTA, 2012).

Nas turmas da EJA, o professor deve criar situações em que os educandos exponham e reconheçam aquilo que já sabem sobre a escrita. Baseando-se no que os alunos já sabem, de acordo com suas experiências, vivências, é que o professor poderá decidir que novas informações fornecerem, quais assuntos deve dar ênfase, de modo que o 
aluno vá elaborando seus conhecimentos até chegar a um domínio autônomo desse sistema de representação.

De acordo com Arruda (2010), essa modalidade de ensino - EJA - não é uma parte complementar ou extraordinária do esforço que a sociedade aplica em educação, mas um setor necessário do desempenho pedagógico geral, ao qual a comunidade se deve lançar. Portanto, em janeiro de 2003, o MEC anunciou que a alfabetização de jovens e adultos seria uma prioridade do novo governo federal.

\section{A RELEVÂNCIA DE APRENDER A LÍNGUA INGLESA NA EJAI}

A abordagem acerca da relevância da Língua Inglesa na concepção afetiva do jovem toma por base os ensinamentos de Schütz (2003), ao afirmar que, por causas de ordem biopsicológicas, quanto mais cedo, o jovem tiver contato com a Língua Inglesa (LI), mais aprimorado será o seu ritmo de assimilação da suposta língua. Cita Brown (2001), que a linguagem é desenvolvida mais eficazmente durante a infância.

Assim, essa perspectiva leva a verificação da importância do emprego da LI não só na EJA, mas também, no ensino fundamental, de maneira que desenvolva as potencialidades individuais e, também, o trabalho coletivo. Isso requer uma estimulação à autonomia do sujeito, visando o desenvolvimento do sentimento de segurança relacionado às suas capacidades específicas. Desse modo, o educando pode compreender que por intermédio do seu trabalho e esforço, ele pode modificar e intervir no espaço onde vive, e que a instituição escolar é um dos caminhos para que essa situação ocorra (CHAGURI, 2005).

É essencial que os alunos sejam mediados pelos educadores para que adquiram uma aprendizagem em uma segunda língua, considerando as suas especificidades e o interesse em adquirir essa aprendizagem. Nesse contexto, poderá se formar alunos críticos, autônomos e participativos, para agir com competência e responsabilidade na sociedade em que residem, empregando sua língua materna ou segunda língua, sendo competentes para a comunicação entre os pares e para agir como cidadãos, capazes de construir de maneira eficaz, a sua própria história. 


\section{A INSERÇÃO DE METODOLOGIAS DIVERSIFICADAS NO ENSINO DA LÍNGUA INGLESA}

Por mais paradoxal que pareça, certos dados acerca da situação que se encontra o ensino de língua inglesa nas instituições oficiais tanto da EJA quanto do ensino fundamental evidenciam sua inadequação, pois os alunos não sabem português, quiçá, o inglês. Faz-se necessário o uso de metodologias diversificadas para dinamizar a aprendizagem da língua e o estudo da mesma. A prática dessa disciplina tem sido feita de forma mecânica e tradicional. Aulas monótonas e repetitivas, fora dos contextos reais dos alunos, além da desmotivação por parte de docentes e discentes e a tentativa do ensino de assuntos irrelevantes à formação educacional, que comprometem a aquisição dos conteúdos da disciplina (CARVALHO, 2014).

É possível tornar as aulas de inglês algo prazeroso para os alunos, trabalhando conteúdos que serão intertextualizados com situações reais do cotidiano dos alunos e da sociedade, mostrando como o inglês está inserido no dia a dia e desenvolver a autoconfiança para que os alunos acreditem na capacidade de aprender. É necessário que se elimine a resistência das crianças e adolescentes à aquisição de um idioma, de forma a conscientizá-los que o inglês dá acesso à ciência, à tecnologia moderna, à comunicação intercultural e ao mundo dos negócios, em um futuro próximo.

Em relação à aprendizagem, é possível dizer que a aprendizagem de uma língua "reaviva processos internos de desenvolvimento que só acontecem quando a pessoa interatua com outros indivíduos" (OLIVEIRA, 1993, p. 33). Um dos motivos para se ensinar a língua inglesa para a EJA deriva-se da curiosidade nata que possuem, e este é um enorme fator de motivação que, por sua vez, é fundamental ao aprendizado.

Assim, conforme assevera Chaguri (2005), as aulas de LI para a EJA, jovens e crianças, necessitam ser lúdicas e dinâmicas, para que estes se sintam atraídos em aprender uma segunda língua que não é a língua materna. Desse modo, para se ensinar a língua inglesa, a princípio, não é preciso primar pela perfeição, pronúncia correta, tradução impecável, entretanto, deve-se estimular o aluno a buscar se expressar na LI sem receios. Um dos fatores essenciais que se deve ter é em se 
tratando do trabalho com qualquer LE é o vocabulário, que precisa ser aprendido trabalhando-se com a utilização de objetos como referência ou ainda, pode ser usada à representação de material audiovisual (slides, data show). Para melhoria da pronúncia, é indicado o uso de CD's, em que o aluno ouça um nativo da língua quando houver necessidade.

O educador, nesse âmbito, precisa explanar as suas aulas, dando a matéria de maneira atrativa e significativa para determinada faixa etária e adequação da série, empregando o uso de jogos educativos, vídeos, músicas, entre outros instrumentos didáticos e metodologias que auxiliarão na fixação do conteúdo. Brown (2001) concebe a tese de que é preciso ensinar LI desde cedo às crianças, pois elas devem ser centradas na iniciação da aprendizagem de uma língua estrangeira, porque quanto mais cedo ficam expostas a uma palavra por um tempo mais longo, maior será a retenção dessa palavra; logo o pesquisador crê que, quanto mais cedo, o jovem se engajar no processo de aprendizagem de uma segunda língua, mais cedo assimilará esse novo vocabulário. $\mathrm{Na} \mathrm{EJA}$, os jovens que nunca viram essa língua antes, sentem dificuldades em aprendê-la.

À medida que a LI é apresentada através de aulas descontraídas e com atividades lúdicas, os alunos da EJA são estimulados a desenvolver uma maior capacidade de concentração. Cabe ao educador dar qualidade ao processo de ensino-aprendizagem, desenvolvendo práticas didáticas inovadoras (NUNES, 2004). Contudo, o educador não deve embasar as suas aulas, apenas em teorias gramaticais repetitivas, visto que o aluno necessita aprender uma Língua Estrangeira - LE mais dinâmica, ficando mais motivado a aprender inglês.

Por fim, conforme Chaguri (2005), aprender outra língua que não a materna, precisa ter início, nas séries iniciais, sempre que ocorrer a possibilidade, sendo esse um direito que não deve ser negligenciado a nenhuma criança, porquanto que ela passa a ter compreensão das competências e habilidades que devem ser desenvolvidas no percurso do seu período escolar. Assim, quando jovens, assimilam mais rápido, a aprendizagem de uma LE. 
Dessa forma, ao ensinar a LI na EJA, o aluno, mesmo sem conhecimento, a priori, vai aprendendo, paulatinamente, a se comunicar, nos mais diversos ambientes, inclusive fora do seu contexto escolar. O mediador dessa aprendizagem, o educador, vai capacitando esse aluno para que possa interagir satisfatoriamente à sociedade de maneira influente e transformadora, para construir uma nova identidade e uma nova mentalidade.

\section{VIVENCIANDO O PROCESSO DA INSERÇÃO DA LÍNGUA INGLESA NO COTIDIANO DA EJA DE UMA ESCOLA MUNICIPAL}

Foram vastas as experiências adquiridas na pesquisa de campo em Língua Inglesa, que teve um público alvo homogêneo, os alunos da EJA da Escola Municipal João Mendonça. A experiência foi relevante e prazerosa, visto que, muito se aprende com o outro, pois com a interação e carinho existentes entre aluno/professor, a aprendizagem se deu de forma significativa. A práxis pedagógica é a que mais ensinamento trouxe, porque sai-se do abstracionismo e passa-se a trabalhar o concreto, uma vez que vivenciando as novas experiências com os alunos, aprendese na prática, mais ainda do que com as teorias e conteúdos programáticos.

No primeiro instante, foi efetuado o diagnóstico da turma, através de atividades e perguntas, para revelar o grau de desenvolvimento. Este procedimento se estendeu em forma de avaliação processual e contínua durante o período da pesquisa, servindo como uma maneira de desenvolver nos discentes, as habilidades da leitura, escrita de números e produção de pequenos diálogos e desenhos EM língua inglesa. A avaliação se deu de forma oral e escrita. A primeira atividade foi realizada a partir da audição de pequenos diálogos e repetição dos mesmos, e posteriormente, desenhos de números, com a feitura dos nomes, feitos individualmente. Através dessas atividades houve a possibilidade de treinar a capacidade dos alunos e seu conhecimento prévio. Algumas dificuldades foram perceptíveis nos alunos que já apresentavam problemas com a língua portuguesa e, portanto, mais dificuldade na assimilação da língua inglesa e variaram de acordo com a complexidade de cada período e do nível de habilidade de cada indivíduo. 


\section{METODOLOGIA}

Através dos textos propostos no primeiro trimestre, foram trabalhadas as quatro habilidades principais da língua inglesa que são: considerações orais - que foram enfatizadas no momento em que o diálogo ia sendo ouvido na caixa de som para que os alunos fossem assimilando algumas palavras do diálogo e fossem capazes de interpretá-las; fala - desenvolvida no momento em que se fez perguntas sobre o texto que os alunos ouviram; escrita - habilidade desenvolvida nos momentos das atividades do livro didático adotado; e a leitura - desenvolvida com o próprio texto que foi estudado. A participação coletiva neste caso é fundamental para que o entusiasmo esteja presente no decorrer da leitura facilitando o aprendizado. E as atividades foram realizadas com êxito pelos jovens da EJA.

Nas aulas ministradas foram aplicadas metodologias que aproximaram o conteúdo à realidade para que a prática fosse compreendida pelo aprendiz. E como exemplo, pode-se citar o ensino do verbo "there to be", no qual foram utilizados objetos dos próprios alunos. Em uma mesma metodologia, aprenderam dois conteúdos de gramática, o verbo acima citado e algumas preposições - "There is a pencil on the table" - sem a preocupação de decorar conteúdos, apenas praticando-os. E assim fizeram com outros objetos e em outras situações. $\mathrm{Na}$ aplicação dos números ordinais do $1^{\circ}$ ao $20^{\circ}$, após eles acompanharem o "listening" e repetirem, formaram uma fila e cada um de acordo a ordem disse: "I am the first", "I am the second", entre outros. Assim, eles assimilaram o conteúdo e tiveram maior facilidade em aplicá-lo no cotidiano. Pois, segundo Bordenave e Pereira (2008), o segredo do bom ensino é o entusiasmo do professor que vem de seu amor à ciência e aos alunos. Entusiasmo a ser canalizado mediante planejamento e metodologias visando incentivar o entusiasmo dos alunos, para uma melhor aprendizagem.

No desenvolvimento do estudo foi usada a intertextualidade para buscar elementos do cotidiano que poderiam ser introduzidos de forma criativa no contexto dos assuntos que estavam sendo trabalhados. E os elementos utilizados foram objetos, palavras, neologismos, músicas, inclusive a música em que aprenderam o alfabeto. O objetivo era que, dessa maneira, fosse despertada a curiosidade dos alunos em tentar 
descobrir os significados dos termos e palavras propostas. "[...] ao mesmo tempo em que aumentando o conhecimento da língua materna, no caso do português, por meio de comparações com o idioma estrangeiro em diversos níveis [...]" (PCN, 1999, p. 61).

Depois foi trabalhado o texto "What's this!", onde os alunos treinaram a pronúncia respondendo aos questionamentos da professora. Foi trabalhada também a habilidade de compreensão, pois os textos foram colocados para os alunos ouvirem e a partir daí desenvolverem a interpretação. Os alunos foram levados a identificar a palavra interrogativa "what...?", utilizada quando se quer saber sobre determinado objeto. A partir deste tema proposto, foram apresentados para os alunos alguns folders de agências de turismo da cidade para que passassem a conhecer nomes de lugares e pontos turísticos. Sempre retomando o objetivo proposto da pesquisa que foi o de despertar nos alunos à importância de aprender o inglês visto que este está inserido na sociedade de forma cada vez mais natural.

Ainda no primeiro trimestre foi trabalhado o texto com o tema "I'm from New York!", no qual foi usada novamente, a mesma estratégia do texto anterior no que diz respeito à interpretação na atividade de listening e a pronúncia. Através dos questionamentos, os alunos identificaram as formas verbais básicas da unidade, neste caso o Present Tense como correspondente contractions.

Foi proposto um passeio com a turma, em volta da escola, para induzir ao treinamento da oralidade nas respostas às questões feitas pelo professor sobre o que cada pessoa estava fazendo, uma vez que é importante para o desenvolvimento da habilidade comunicativa oral em língua inglesa.

É importante salientar que em meio ao decorrer da unidade foram desenvolvidas dinâmicas, atividades coletivas e individuais, em que foram utilizadas metodologias várias, inclusive com a utilização de objetos dos alunos para fixação e memorização. Foram utilizados jogos e músicas para que os alunos aprendessem a pronúncia, ouvindo a voz de um nativo da língua inglesa. E usaram-se revistas e jornais observando-se a língua inglesa contida nestes objetos para a compreensão da língua escrita, voltada para o tema proposto na pesquisa, para que o resultado fosse 
satisfatório. Os recursos e materiais utilizados foram: xerox, papel ofício, cartolina, papel cartão, corda, Minysistem, hidrocor, cola, lápis de cor, revista, jornal, durex, tesoura, régua, Cd's, data show, slides.

\section{CONSIDERAÇÕES FINAIS}

Os alunos da Escola Municipal João Mendonça perceberam, ao final da pesquisa, a importância do domínio da língua inglesa nos dias de hoje, em muitos campos. Em um mundo cada vez mais sem fronteiras, comunicar-se é fundamental, estando aí, a chave para o sucesso na vida profissional, nos estudos e mesmo nas horas de lazer. A língua inglesa é falada e estudada em todo o mundo por cerca de 800 milhões de pessoas, tendo-se tornado rapidamente a "língua franca" - a língua comum - das comunicações internacionais. Sabendo inglês, a pessoa consegue se comunicar em qualquer parte do mundo.

Devido ao fato de a língua inglesa ter se tornado um idioma cada vez mais inserido no cotidiano das crianças, adolescentes, jovens e adultos é que se fez necessária a busca do conhecimento, fala e entendimento do "básico" desse idioma na escola em estudo, para despertar nos alunos da EJA, a vontade de aprender uma língua estrangeira, através das leituras, discussões, ensinamentos e reflexões em sala de aula.

Esses estudos destinaram-se aos discentes da EJA com o objetivo de demonstrar a importância do inglês nas suas vidas e a frequência do seu uso no dia a dia, bem como essa ideia deve ser trabalhada, o mais cedo possível, em sua vida cotidiana, já que hoje todos têm contato mais rápido com o mundo moderno, através da internet, ao ouvir músicas na língua inglesa, ir ao cinema, ao fazer compras em um shopping ou super mercado.

Os objetivos deste trabalho foram alcançados, pois a pesquisa realizada propiciou aos alunos condições para que pudessem praticar e se expressar em uma língua estrangeira, estimulando atividades que promoveram a vivência da língua inglesa dentro e fora da sala de aula, oferecendo ao aluno, condições orais e escritas para 
que pudesse utilizar-se da mesma, em seu cotidiano, aprimorando os conhecimentos linguísticos já internalizados; assim como ajudou a desenvolver nos alunos, a capacidade de se comunicar em língua inglesa, dentro do contexto do conteúdo programático, no sentido de desenvolver o raciocínio lógico, a autocrítica, em relação à compreensão do mundo, no contexto sócio-político e econômico, para que possam refletir sobre o papel da língua inglesa no mundo atual.

É interessante ressaltar que foi planejado este trabalho para observar que na escola pública com alunos da EJA também se pode aprender inglês de forma qualitativa. Ao final da pesquisa, quase todos obtiveram êxito. Alguns que já tinham dificuldade na língua materna, também apresentaram dificuldades iniciais, mas foram contornadas, visto que foram usados recursos audiovisuais para facilitar a aprendizagem. Ficou evidenciada a efetiva participação de todos nos trabalhos e atividades, o que os habilitou a reconhecer nas formas faladas e escritas, as ideias e conteúdos vistos em língua inglesa na unidade.

Foi perceptível que os alunos passaram a entrar em contato com o universo e com a cultura que a língua estrangeira representa, com possibilidades de analogias e diferenciações enriquecedoras de sua experiência; e se interessaram pela leitura de livros, revistas, canções, bem como habituarem-se à consulta a dicionários e livros de referências; e o alunado da EJA passou a conhecer e usar a língua inglesa como instrumento de acesso a informações e a outras culturas e grupos sociais. O resultado alcançado com os alunos foi satisfatório, uma vez que a turma, em quase sua totalidade, conseguiu atingir uma aprendizagem significativa.

\section{REFERÊNCIAS}

ALMEIDA, Ricardo Luís Teixeira de. The teaching of English as a foreign language in the context of Brazilian regular schools: a retrospective and prospective view of policies and practices. RBLA, Belo Horizonte, v. 12, n. 2, p. 331-348, 2012.

\section{ARRUDA, Gutembergue da Silva. 0 ensino da disciplina processo de fabricação na educação de jovens e adultos, do curso de técnico em mecânica do}


CEFETAM.

$<$ http://portal.mec.gov.br/setec/arquivos/pdf3/tcc_oensino.pdf>. Acesso em: 24. maio 2019.

BORDENAVE, Juan Díaz; PEREIRA, Adair Martins. Estratégias de ensinoaprendizagem. 29 ed. Petrópolis, RJ: Vozes, 2008.

BROWN, H. Douglas, Teaching by principles: and interactive approach to language pedagogy. $2^{\text {nd }}$ ed. San Francisco: State University, 2001.

CAMPOS, Giovana Teixeira. Gramática língua inglesa: teoria e prática. São Paulo: Rideel, 2006.

CARVALHO, Kalaff Ribeiro. A relevância da língua inglesa na educação de adolescentes, jovens e adultos. Revista Eletrônica de Educação da Faculdade Araguaia, 6: 293-308, 2014.

CHAGURI, Jonathas de Paula. A importância do ensino da língua inglesa nas series iniciais do ensino fundamental. In: 0 desafio das letras, 2., 2005, Rolândia: Anais... Rolândia: FACCAR, 2005.

CNA-CASA VERDE. Historia da Língua Inglesa: Como tudo começou..., 2005. Disponível em: < http://www.cnacasaverde.com.br/cna/curiosidades/hitdoingles.htm>. Acesso em: 10 mai. 2019.

NUNES, Ana R. S. Carolino de Abreu. O lúdico na aquisição da segunda língua. Disponível em:<http: //www.linguaestrangeira.pro.br/artigos_papers/ludico_linguas.htm>. Acesso em 11 abr. 2019.

OLIVEIRA, Marta Kohl de. Vygotsky aprendizado e desenvolvimento: um processo sócio-histórico. São Paulo: Scipione, 1993.

PCN. Parâmetros Curriculares Nacionais, Códigos e suas Tecnologias. Língua estrangeira moderna. Brasília: MEC, 1999. 
SCHÜTZ, RICHARD. O que é talento para Línguas? English made in Brazil. Disponível em: <http://www.sk.com.br/sk-talen.html>. Acesso em: 06 maio. 2019.

TAMAROZZI, Edna; COSTA, Renato Pontes. Educação de Jovens e Adultos.

Curitiba, PR: IESDE Brasil, 2012.

Enviado: Junho, 2019.

Aprovado: Julho, 2019. 